\title{
Life-Cycle Sustainability Assessment in the Design of Concrete Structures in the Tropics: A Fundamental Analysis
}

\author{
Farnaz Jahandideh ${ }^{1}$, Sudharshan N. Raman ${ }^{2 *}$, Maslina Jamil ${ }^{3}$, R. Prakash ${ }^{4}$, \\ ${ }^{1,3}$ Department of Architecture and Built Environment, Faculty of Engineering and Built Environment, \\ Universiti Kebangsaan Malaysia, 43600 UKM Bangi, Selangor, Malaysia \\ ${ }^{2}$ Civil Engineering Discipline, School of Engineering, Monash University Malaysia, Jalan Lagoon \\ Selatan, 47500 Bandar Sunway, Selangor, Malaysia \\ ${ }^{4}$ Department of Civil Engineering, Alagappa Chettiar Government College of Engineering and \\ Technology, Karaikudi, Tamilnadu 630 003, India
}

${ }^{1}$ fzjahandideh@gmail.com, ${ }^{2 *}$ snraman@gmail.com, ${ }^{3}$ pghinovasi@ukm.edu.my, ${ }^{4}$ rprakash024@gmail.co $m$

Published: $31^{\text {st }}$ December 2020

Due to the essential nature and increased appreciation to the issue of sustainability in recent decades, the evaluation and assessment of environmental impacts of concrete structures have been considered extensively by the scientific and construction fraternity. To enhance the resilience in the design of concrete structures in the tropics, it is essential to understand and acknowledge the impact of the geographical context, taking into account the widespread socio-economic circumstances in the tropics. Moreover, since all environmental impacts of a concrete structures through its life-cycle use are predictable through its Life-Cycle Sustainability Assessment (LCSA), it is therefore necessary to investigate this framework comprehensively. This research was undertaken to study and assess the existing methods in LCSA, as well as to assess the steps and materials that can significantly affect the environment during the whole life-span of concrete structures, and also to qualitatively understand the interaction among the geographic sense and sustainability in the tropics, considering the case of Malaysia. This study proposes a more comprehensive framework for LCSA in the design of concrete structures. The findings suggest that according to LCSA analysis, the environmental effects of concrete structures with almost the same functional quality can be different from each other.

Keywords: Concrete structures, Construction, Design, Life-cycle sustainability assessment (LCSA), Sustainability, Tropics

\author{
Abbreviations: \\ LCA: Life-Cycle Assessment; \\ LCSA: Life-Cycle Sustainability Assessment; \\ ELCA: Environmental Life-Cycle Assessment; \\ SLCA: Social Life-Cycle Assessment; \\ LCC: Life-Cycle Cost; \\ LCI: Life-Cycle Inventory; \\ LCIA: Life-Cycle Inventory Assessment; \\ EMoC: Environmental Model of Construction; \\ SMoC: Social Model of Construction; \\ CMoC: Cost Model of Construction.
}




\section{INTRODUCTION}

Concrete structures contribute to significant environmental impacts which is rooted in its high investment in terms of raw materials and energy consumption in material production, construction and building operation phases. The sustainability of concrete structures and reducing its impact on the environment has attracted the attention of construction researchers and practitioners, and the associated issues are expected to be further intensified in the future. Jahandideh et al. (2020) stated that the need to address the sustainability aspect of concrete structures in hot and humid climatic conditions, and the material and resource effectiveness during the concrete production stage have been a concern in many studies. With increasing population growth, the average global concrete consumption rate can exceed the average of $1 \mathrm{~m}^{3}$ per person annually, i.e. possibly exceeding 10 billion $\mathrm{m}^{3}$ annually in coming years. Along the same line, Lippiatt and Ahmad (2004) has highlighted that two essential issues govern the concept of performance-based sustainable design, which are, feasible estimation of the variables correlated with the performance assessment method, and the effective description of the underlying structural sustainability for explicit integration into the design or performance assessment.

Concrete, being the most commonly and widely used construction material for buildings and infrastructures across the globe, also due to the increase in global population, and in parallel, discovering the amazing benefits of this material can be attributed to particular attention to it, especially in developing countries (Nor et al., 2019). Accordingly, introducing and presenting novel solutions for identifying and evaluating its environmental impacts accurately are pressing issues concerning concrete structures (Hamzah et al., 2019). In these type of studies, the data collection of the life-cycle inventory is the main restriction, where, there were also data absent or originating from various common databases which reported results in a lack of precision and clarity (e.g. different geographical representative) (Finnveden et al., 2009). Due to these limitations, the outcomes of these studies relied primarily on the different hypotheses and collected data, analytical options, construction methodologies or building system variation based on the proposed region; consequently, the findings and results cannot be contextualized and ought to be considered properly (Boulenger, 2011).
Past investigations have shown that issues dependent on the Life-Cycle Sustainability Assessment (LCSA) and sustainable concrete structures include the effects of negative community viewpoints on the use of reclaimed products, the significance of sustainability given changes in the world, the necessity for environmental awareness, as well as recognition of appropriate value parameters (Woon et al., 2019). Nevertheless, the effects of environment, geographical and economic variables have not been fully demonstrated, especially since they contribute to environmental impacts as an essential part of enhancing concrete sustainability (Fiala et al., 2013).

In order to develop a variety of information on the environmental sustainability of concrete structures in the tropics, the connection between such variables and sustainability should be recognized. Also, several studies dealing with the environmental assessment of structures have recently been conducted for sustainability purposes (Pradipto and Afif, 2019). Most of these studies emphasize on life-cycle analysis of structures in American and European territories with various structures, performance, application, or concept. The relevant building output should, therefore, be set specifically as fundamental factors when determining the scope of the system of an environmental sustainability appraisal through concrete life-cycle assessment (Besten et al., 2018). Thus, the main objective of this study is to identify new solutions for the design and construction of concrete structures in accordance with the principles of sustainable development, which should be followed at all stages throughout the life-cycle of the structure from the provision of resources and materials to the stage of destruction and disposal of waste. Moreover, this paper proposes a comprehensive model providing the advantage of tentatively specified criteria for a comparable LCSA of concrete structures in the tropics.

\section{BASIC CONCEPT OF LIFE-CYCLE SUSTAINABILITY ASSESSMENT}

Prior studies in this area indicated several critical issues concerning environmentally friendly concrete, including the responsibilities of relevant parties in the development and implementation of innovative techniques, and the establishment and implementation of relevant standards and guidelines, the influence of reprocessing with 
regard to the deterioration of resources, and the impact of adverse social belief on the use of recyclable materials (Sharif et al., 2017). Nevertheless, the impact of aspects that contribute to environment, geography, and economics was not demonstrated clearly, especially with regards to efficiency in durability as an essential means of promoting concrete sustainability.

LCSA of concrete structures can be defined as a methodology template for identifying issues related to concrete structures and assessing how they impact the environment during the life-cycle of the structure, from cradle to grave (ISO 14040, 2006 \& ISO 14044, 2006). LCSA has four different phases. The determination of the aims, goals and scope, the organizational boundaries, and the placement of appropriate functional units, is considered as the first step. The second step involves the inventory of the life-cycle (LCI), which is the mechanism of data collection of related variables of all stages of a product's lifecycle. The life-cycle impact assessment (LCIA) is the third step that will use LCI data to determine the capacity of the environmental impacts of resource estimation. The final step is to interpret and explain of the issues above and the resulting outcomes. In this phase, the final results are reviewed and the constraints are identified.

Finally, according to the evaluations carried out, suggestions are made to improve the conditions (Bribian et al., 2011). Also, the basic LCSA can be evaluated in three separate areas. Figure. 1 introduces the proposed pathway in the evaluation of the life-cycle assessment of concrete structures established upon the recommendation proposed by Hajek et al. (2011), based on the three different areas identified from various scientific studies in this field.

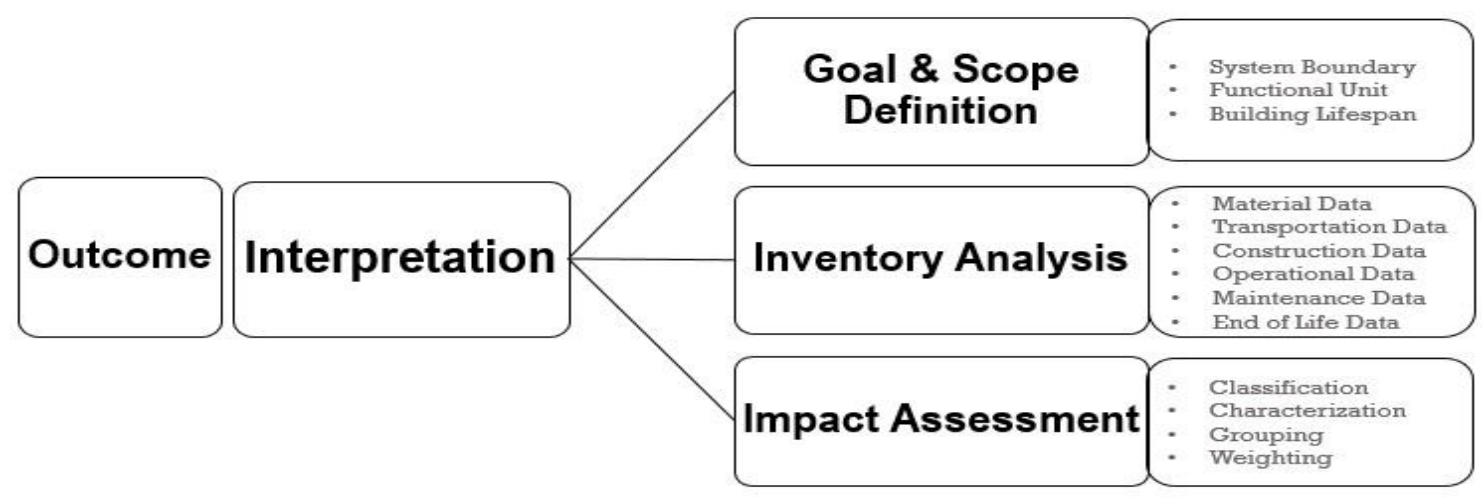

Figure 1. The basic LCSA Framework for the concrete structures industry. Adapted from Hájek et al. (2011).

The LCSA assesses the performance of sustainability of a structure through its life-cycle by examining three main aspects of sustainability, i.e., environment, economy and society (Schau et al., 2012). Finkbeiner et al. (2010) has defined LCSA as the combination of Lice-Cycle Analysis (LCA), Life-Cycle Costing (LCC) and Social Life-Cycle Assessment (SLCA), i.e.:

$$
\mathrm{LCSA}=\mathrm{LCA}+\mathrm{LCC}+\mathrm{SLCA}
$$

(Finkbeiner et al., 2010)

\section{ATTRIBUTIONAL AND CONSEQUENTIAL LCSA}

Finnveden et al. (2009) discussed on two types of LCSA. The first emphasizes on describing "environmentally relevant physical flows to and from a life-cycle and its subsystems", and explains how the "mechanical and physical environmental flows associated with the lifecycle of a structure and its related subsystems". Meanwhile, the second is consequential LCSA, which is with a view of finding an answer to "how potential change in executive decisions can change the way to environmental issues" (Finnveden et al., 2009). These concepts are entirely linked to two separate major information categories: average and marginal. To help comprehend the contrast between these two types of data, we will refer the Figure 2. 


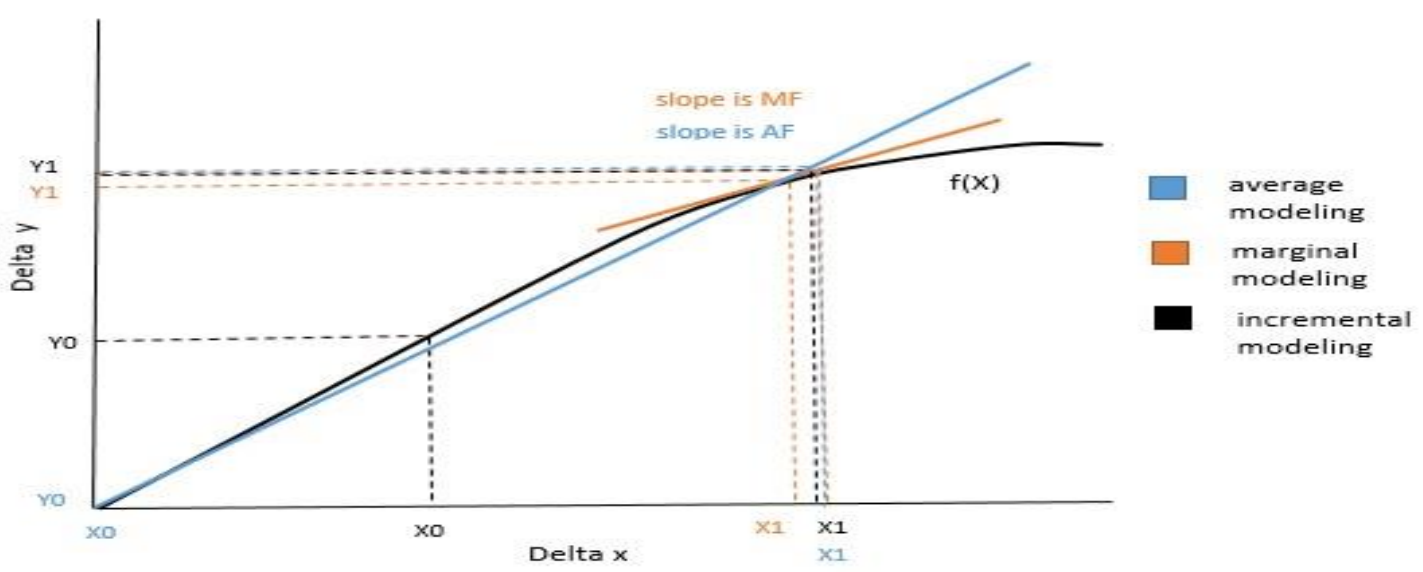

Figure 2: Different types of modeling. Adapted from Boulenger (2011) and Guinee et al. (2001).

These two forms of model are related to two independent definitions of this curve. While the average gradient is in the middle of the work points and the curve begins, the marginal gradient with the local slope is located at a specific point of the curve that can compute the effect of the smallest changes on the environmental burdens system. As a result, the magnitude of these changes should be modest enough to allow the curve to be linearized (Boulenger, 2011). On the other hand, the average environmental burden of a material or structure can be estimated through the average of overall data, which, of course, attributional LCSA does not include marginal information, but is often used in syntactic LCSA (Finnveden et al., 2009).

\section{METHODOLOGY}

The LCSA methods and simulations will analyze all the significant environmental consequences of utilization of a concrete built system (buildings, bridges, tunnels, etc.) during the life-cycle (from "cradle to grave") (Hossaini et al., 2015). This covers all the processes of life-cycle, including how to plan and procure raw materials used to construct thorough examination of the structure and service to destruction and reuse of materials or waste management (Caruso et al., 2017).

The initial quality of a concrete structure used during its construction can determine the quality level of that construction over its life-cycle. For this reason, to lower the operating costs or environmental costs that are imposed at the end of the life-cycle of a building, it would be better with a higher initial investment to achieve a higher quality structure (García-Rey and Yepes, 2012).
As the concept of the LCSA expanded, and through the critical analysis of literature as well as through detailed analytical work by the authors of this paper, the authors have proposed to incorporate the concepts of Environmental LifeCycle Assessment (ELCA), together with LCC and SLCA into the structure of LCSA. This proposed framework has been presented in the next section.

In this study, a methodology for LCSA of concrete structures is proposed on the basis of approaches recommended in ISO 14040, ISO 14044 and associated with a set of international standards. The main purpose of this research is to identify the gaps in past researches on sustainability assessment of concrete structures. Also, to identify and analyze the environmental factors contributing to concrete structures, which through analysis, their results can provide solutions for the improvement and development of sustainable environments, especially in the tropics. LCSA is composed of four different stages as proposed in ISO 14040 (2006), as described below:

- Defining the intent and context: To identify all preliminary concerns related to LCSA study, a review of motives will be conducted, along with the scope and content of the evaluation.

- Inventory estimation: It usually includes the collection of statistical data to evaluate all materials, energy, and environmental impacts assumed as variables throughout the system life-cycle.

- Influence evaluation: Which is mainly associated with the translation of data 
- retrieved from the inventory into results and environmental consequences linked to the output of the system evaluated.

- Explanation and interpretation: This phase describes the findings achieved during the processes of the inventory and/or effect analysis, and provides findings and suggestions.

\section{RESULTS AND DISCUSSION}

As the concept of the LCSA expanded, further to the concept presented in Eq. 1, and through the critical analysis of literature as well as through detailed analytical work by the authors of this paper, the authors are proposing to incorporate the concepts of ELCA, together with LCC and SLCA into the structure of LCSA, as following:

$$
\mathrm{LCSA}=\mathrm{ELCA}+\mathrm{LCC}+\mathrm{SLCA}
$$

This concept is presented in Figure 3, which illustrates the description of LCSA framework method for buildings, as proposed by the authors. The concepts of Environmental Model of Construction (EMoC), Social Model of Construction (SMoC) and Cost Model of Construction, which have been incorporated into the framework model (Figure 3) have been derived from the model proposed by Dong et al. (2016).

According to the proposed LCSA framework, Life-Cycle Impact Assessment (LCIA) will be undertaken based on estimated quantities or Bill of Quantities of building drawings and field measured data (Iyer-Raniga and Wong, 2012). The significant intuition in this phase is to assess the quantity of concrete and its ingredients in production and construction of the structure (AlJebouri et al., 2017).

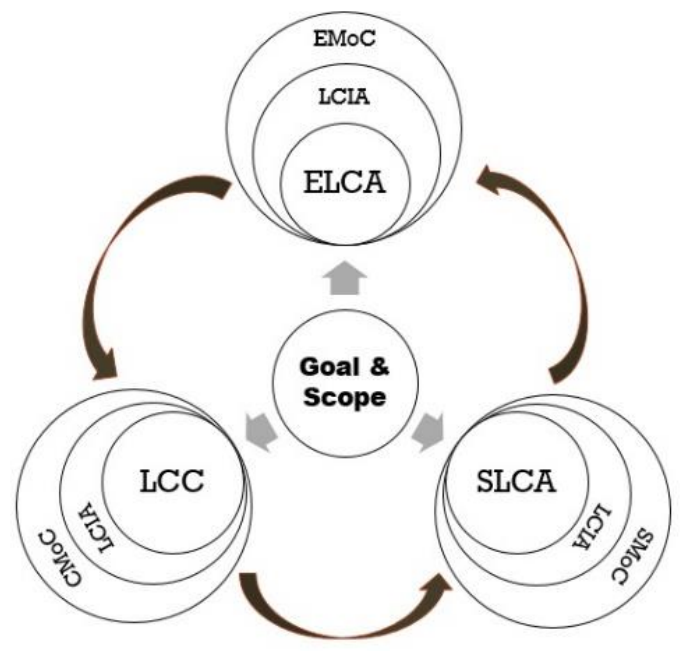

Figure 3. The enhanced LCSA framework model for concrete structures proposed by the authors of this study. These concepts have been adapted and developed from the models proposed by Dong and Thomas (2016), Al-Jebouri et al. (2017), and Heijungs et al. (2010).

According to the study by Lemay (2011), based on past studies in relation to LCSA as well as other available resources that have emphasized on reinforced concrete buildings and structures up to 2011, it was deduced that out that the importance of the LCSA studies have been discussed by more than $59 \%$ of studies which were reported from 2005 to 2009. The results on the given chart (Figure 4) were obtained while focusing on the methods used for LCSA framework. 


\title{
PUBLICATIONS METHODOLOGY
}

\author{
used process method completed the LCIA step \\ घ used for the study's calculations " performed a sensitivity analysis
}

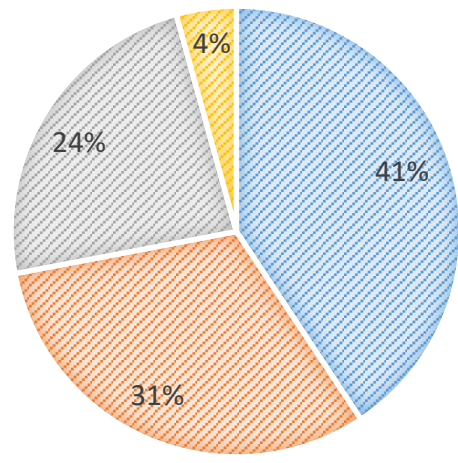

Figure 4: Methodologies adopted for publications relating to LCSA, adapted from Lemay (2011)

Also, comparison of different strategies is achieved through sensitivity analysis, not as an intra-system analysis (Arup and Partners, 2007). In order to achieve the weaknesses in concrete structures of the case study, which in this article is Malaysia; and its climatic conditions, also based on the deficiencies and limitations in this direction, revealed the shortcomings and problems in the paths of LCSA studies that include:

- The lack of definition and explanation in relation to the inventory stage, as well as in several sources of information acquisition is uncertain.

- The lack of a complete and correct interpretation of various parts on the functions that leads to problems in the next comparisons of other studies.

- The lack of a precise definition of barriers and assumptions of LCSA studies that significantly affect the result presentation of other studies.

- The complete elimination of the life-cycle of concrete structures from its operational stage within the framework of the study (ISO 14040, 2006).

- Given that the possible environmental impact assessment of the concrete structures has not been considered, it can be said that existing studies have limitations and lack clarity of information.

- Lack of graphical expression in relation to the interpretation and justification of the studies (Arup and Partners, 2007).

On this basis, it may have been ascertained that the lack of consistency, reduced consistency and steep ambiguity was the most significant shortcomings, in LCSA studies on the sustainability of concrete structures (García-Rey and Yepes, 2012). Moreover, according to previous studies in LCSA of concrete structures, between all the four life-cycle stages, the operation phase is most responsible for energy consumption in the building life-cycle and based on the building location which is in tropical region, space cooling was considered as the highest energy consumer (Baharun et al., 2018).

The majority of researches on sustainability of concrete structures have indicated that cement is the main factor in $\mathrm{CO} 2$ emission and environmental impacts of these structures, and the use of supplementary materials should be exploited across the globe to further drive the sustainability agenda (Chan, 2019).

\section{CONCLUSIONS}


The LCSA approach is one of the most feasible methods in evaluating the environmental impact of a product/process over its life-cycle. While the field of LCSA of concrete structures still evolving and needs further research, development and understanding, it is evident from the findings reported herein that the achievement of a sustainable and environmentally friendly concrete structures in each region is dependent on its particular and varying conditions. This study demonstrated that sustainable regional resource procurement is the most essential aspect that may affect models of sustainable concrete construction incentives. The authors have proposed an updated framework model for LCSA of concrete structures by integrating the concepts of ELCA, together with LCC and SLCA.

The findings further suggest that the high quality technical and ecological performance increases the opportunity for broader use of special types of concretes in future concrete structures. It means that according to detailed LCSA analysis, the environmental effects of concrete structures with almost the same functional quality can be very different from each other. This affects not only the different amounts of concrete used in the structure, but also various components associated to the construction, such as transportation and production. Access to input data from accurate inventory analysis established upon particular data sources in each region can be effective in use and improvement of quality of LCSA studies. In addition, the unique environmental and regional characteristics have a great influence on the LCSA process. The next step in the integrated assessment of the life-cycle is complexity of concrete structures, which has three main pillars: environmental sustainability, social sustainability and economic sustainability.

As mentioned, the LCSA approach needs to develop goals that are influenced by its core aspects. With the development of such studies, more precise and comprehensive information on the effects and sustainability of concrete structures in tropical regions can be obtained. Improving the quality level of studies should be undertaken through consideration for available resources. Accordingly, increasing the resources and databases can improve the quality and accuracy of the findings and output.

\section{ACKNOWLEDGEMENT}

This work was supported by the Ministry of Higher Education, Malaysia through the FRGS Grant (FRGS/1/2019/TK01/UKM/02/2).

\section{REFERENCES}

1. Al-Jebouri, M.F.A., Saleh, M.S., Raman, S.N., Abdullah, R.A, Shaaban, A.K. (2017), Toward a national sustainable building assessment system in Oman: Assessment categories and their performance indicators. Sustainable Cities and Society 31:122-135. https://doi.org/10.1016/j.scs.2017.02.01 $\underline{4}$

2. Arup and Partners Hong Kong Ltd. (2007). An introduction to life cycle energy assessment (LCEA) of building developments, Hong Kong. 55-57.

3. Baharun, A., Syukri Imran, M., Ibrahim, S.H., and Wan Zainal Abidin, W.A. (2018), Night cooled radiant cooling panel for sustainable building cooling mode in Malaysia. Journal of Construction in Developing Countries 23(1):61-79. https://doi.org/10.21315/jcdc2018.23.1. $\underline{4}$

4. Besten, V., Berawi, M.A., Latief, Y., Crevits, I. (2018), Building incentive structure in the context of green building implementation: From the local government perspective. Journal of Design and Built Environment 18(2): 37-

45.https://ejournal.um.edu.my/index.ph $\mathrm{p} / \mathrm{jdbe} /$ article/view/15580

5. Boulenger, M. (2011), Life cycle assessment of concrete structures using public databases: comparison of a fictitious bridge and tunnel. Master of Science Thesis, Royal Institute of Technology (KTH). Stockholm, Sweden.

6. Bribián, I. Z., Capilla, A. V. Usón, A. (2011), Life cycle assessment of building materials: Comparative analysis of energy and environmental impacts and evaluation of the eco-efficiency improvement. Building and Environment 
46(5):

1133-1140.

https://doi.org/10.1016/j.buildenv.2010. $\underline{12.002}$

7. Caruso, M. C., Menna, M., Asprone, D., Prota, A., Manfredi, G. (2017), Methodology for life-cycle sustainability assessment of building structures. ACI Structural Journal 114(2): 322-335. https://doi: $10.14359 / 51689426$

8. Chan, T. K. (2019), Building and construction research in Malaysia: $A$ bibliometric analysis. Journal of Construction in Developing Countries 24(1):65-84.

https://doi.org/10.21315/jcdc2019.24.1. $\underline{4}$

9. Dong, Y.H., Ng, S.T. (2016), A modeling framework to evaluate sustainability of building construction based on LCSA. The International Journal of Life Cycle Assessment 21: 555-568. https://doi.org/10.1007/s11367-0161044-6

10. Fiala, C., Novotna, M., Hajek, P. (2013), Methodology of Life-Cycle Assessment of RC Structures Using High Performance Concrete. Central Europe towards Sustainable Building 2013, Decision-Support Tools and Assessment Method. Prague, Czech Republic.

11. Finkbeiner, M., Schau, E. M., Lehmann, A., Traverso, M. (2010), Towards life cycle sustainability assessment. Sustainability 2(10): 3309-3322. https://doi.org/10.3390/su2103309

12. Finnveden, G., Hauschild, M.Z., Ekvall, T., Guinée, J., Heijungs, R., Hellweg, S., Koehler, A., Pennington, D., Suh, S. (2009), Recent developments in life cycle assessment. Journal of Environmental Management 91(1): 1-21. https://doi.org/10.1016/j.jenvman.2009. $\underline{06.018}$

13. García-Rey, J., Yepes, V. (2012), Environmental assessment of concrete structures. Int. Journal of Construction Engineering and Management 1(3): 3341. doi: $10.5923 /$ j.ijcem.20120103.04
14. Guinée, J.B., Gorrée, M., Heijungs, R., Hupper, G., de Kleijn, A., van Oers, L., Wegener Sleeswijk, A., Suh, S., Udo de

15. Haes, H. A., de Bruijn, H., van Duin, R., Huijbregts, M. A. J. (2001), Life Cycle Assessment-An operational guide to the ISO Standards. Ministry of Housing, Spatial Planning and the Environment (VROM) and Centre of Environmental Science - Leiden University (CML).

16. Hájek, P., Fiala, C., Kynčlová M. (2011), Life cycle assessments of concrete structures - A step towards environmental savings. Structural Concrete 12(1): 1322.https://doi.org/10.1002/suco.201000 $\underline{026}$

17. Hamzah, N., Cheon Weng, L.E., Kamaruzzaman, S.N, Wong, P.F, CheAni, A.F, Khoiry, M.A. (2019), An environmental study on development of refurbishment assessment themes for heritage nondomestic buildings in Malaysia. Ekoloji 28(107): 3-15. http://ekolojidergisi.com/article/anenvironmental...

18. Heijungs, R., Huppes, G., Guinée, J.B. (2010), Life cycle assessment and sustainability analysis of products, materials and technologies. Toward a scientific framework for sustainability life cycle analysis. Polymer Degradation and Stability 95(3): 422-428. https://doi.org/10.1016/j.polymdegradst ab.2009.11.010

19. Hossaini, N., Reza, B., Akhtar. S., Sadiq, R., Hewage, K. (2015), AHP based life cycle sustainability assessment (LCSA) framework: A case study of six story wood frame and concrete frame buildings in Vancouver. Journal of Environmental Planning and Management 58(7): 1217-1241. https://doi.org/10.1080/09640568.2014. $\underline{920704}$

20. ISO 14040. (2006), Environmental management - Life cycle assessment Principles and framework. International 
Organization for Standardization, Geneva, Switzerland.

21. ISO 14044. (2006), International standard. In: Environmental management-life cycle assessmentrequirements and guidelines. International Organization for Standardization. Geneva.

22. Jahandideh, F., Raman, S. N., Jamil, M. (2017), Life cycle sustainability assessment of concrete structures in the tropics. International Conference on Sustainable Cities, Communities and Partnerships for Sustainable Development Goals. Malaysia.

23. Jahandideh, F., Raman, S. N., Jamil, M., Syed, Z. I. (2020), Carbon footprint assessment in the design of concrete structures in the tropics: A case study of residential buildings in Malaysia. Journal of Design and Built Environment 20(2): 27-34. https://ejournal.um.edu.my/index.php/jd be/article/view/25907

24. Lemay, L. (2011), Life Cycle Assessment of Concrete Buildings. National Ready Mixed Concrete Association.

25. Lippiatt, B., Ahmad, S. (2004), Measuring the life-cycle environmental and economic performance of concrete: the BEES approach. In: Wang K, editor. International Workshop on Sustainable Development and Concrete Technology. Ames: Iowa State University. pp. 213230.

26. Iyer-Raniga, U., Wong, J.P.C. (2012), Evaluation of whole life cycle assessment for heritage buildings in Australia. Building and Environment 47: 138-

149.https://doi.org/10.1016/j.buildenv.2 $\underline{011.08 .001}$
27. Nor, J.M., Salman, A.M., Che-Ani, A.I., Layoff, R.A., Washi, W. (2019), Identifying the critical components to extend concrete flat roof service life in equatorial climates: a review. International Journal of Recent Technology and Engineering 7: 281284.

28. Pradipto, E., Afif, N. (2019), Increasing eco-performance of concrete blocks through computational design form optimization. Journal of Design and Built Environment 19(3): 1-12. https://ejournal.um.edu.my/index.php/jd be/article/view/21564

29. Schau, E.M., Traverso, M., Finkbeiner, M. (2012), Life cycle approach to sustainability assessment: a case study of remanufactured alternators. Journal of Remanufacturing (2):1-14. https://doi.org/10.1186/2210-4690-2-5

30. Sharif, S., Kamaruzzaman, S.N., Pitt, M. (2017), Implementation framework of green building for government building: Menara Kerja Raya, Malaysia. Journal of Design and Built Environment 17(2): 27-

36.https://doi.org/10.22452/jdbe.vol17n $\underline{\mathrm{o} 2.3}$

31. Woon, C.O., Raman, S.N., Shafiudin, M.D., Jamil, M., Fauzi, M. (2019) Development of an assessment method to evaluate the quality of remedial treatments on concrete flat roofs of multiple buildings. Buildings 9 (124): 115.https://doi.org/10.3390/buildings905 $\underline{0124}$ 